\title{
HIV/AIDS STIGMATIZATION, THE REASON FOR POOR ACCESS TO HIV COUNSELING AND TESTING (HCT) AMONG THE YOUTHS IN GULU (UGANDA)
}

\author{
'D. L. Kitara and ${ }^{2}$ J. Aloyo \\ ${ }^{1}$ Gulu University, Faculty of Medicine, Department of Surgery \\ P.O Box 166, Gulu, Uganda. ${ }^{2}$ Public health specialist \\ African Centre for Treatment and Rehabilitation of Torture Victims \\ Gulu, Uganda \\ Email: klagoro@yahoo.co.uk, judithaloyozooo@yahoo.com
}

\begin{abstract}
HIV/AIDS-related stigma still exists in many communities in Uganda. Stigma perpetuates discrimination and this may be a key contributor to the spread of HIV/AIDS in this country. Right from the beginning, HIV/AIDS epidemic has been accompanied with fear, ignorance and denial, leading to stigmatization and discrimination against people living with HIV/AIDS and their families. A study conducted by Uganda AIDS Commission (UAC) in Uganda indicated that $64 \%$ of the people who tested for HIV/AIDS did not disclose status to their partners due to fear of stigmatization. A cross-sectional study was conducted in Gulu District, Pece sub County among the youths 15 to 35 years old. A structured questionnaire was administered to 86 consented youths who were consecutively selected. Ethical approval was obtained from Gulu Hospital. Most youths (90\%) practiced stigmatization, (93.1\%) respondents had adequate knowledge on HIV counseling and testing (HCT). However, only (36.1\%) had undertaken HCT and the majority did not do because of fear of stigmatization. There is sufficient knowledge, a positive attitude but a poor practice to HCT. There is high level of HIV/AIDS stigmatization among the youths.
\end{abstract}

Key words: HIV counseling and testing, stigmatization, youths, Gulu (Uganda)

\section{Introduction}

Despite major medical and technological breakthroughs and advances in the early identification and diagnosis of HIV using the most modern laboratory techniques, the AIDS epidemic continues its relentless spread in many resource-poor settings (William, 1988; Cohen et al., 1994; Pratt, 1988) especially among the youths. There is clear evidence in Uganda that the prevalence and incidence of HIV/AIDS is slowly but progressively increasing among youths especially in urban areas despite a series of medical advances in diagnosis and improved management of HIV/AIDS (Wabwire-Mangeni et al., 2008; Kitara et al., 2011).

HIV/AIDS continues to be the most devastating and important global public health and development problems (Edward, 2006; Wabwire-Mangen et al., 2008). However, HIV/AIDS have to compete for resource allocation with other emergencies that constantly threatens the human race, including civil strife, natural disasters and the continuing threats of emerging infectious diseases such as Ebola, SARS and Avian influenza (Cohen et al.,1994; Pratt,1988); Montgomery, 1992). Three key challenges for the future is controlling further spread of the epidemic in the infants and the young adults, counseling, testing and treating, caring for and supporting the neglected millions of people living with HIV/AIDS and the mitigating the epidemic's impact on the millions of people affected by the AIDS in the resource constrained countries (Turner et al., 1988; Margaret et al., 2000; Edward et al., 2006). The wide spread acceptance and the use of blood testing for HIV/AIDS in Uganda has helped reduce the spread of the virus (Mugyenyi, 2008; Edward, et al., 2006). This was achieved through adequate counseling to explain the meaning of the positive test result. Provision of psychosocial support to ease the shock of having a positive test result and the fact that many people accepted the results and pronounced their positive lives in the public without the fear of stigmatization created the biggest impact on the fight against HIV/AIDS and its current prevalence decline from $29 \%$ in the 80 s to less than $10 \%$ in the year 2000 in Uganda (Mugyenyi, 2008; Edward et al., 2006). The role of the political leadership of Uganda and other world leaders in embracing this strategy and emphasizing positive living and ABC preventive messages plus early HCT played a major role in this success (Wabwire-Mangeni et al., 2008; Epstein, 2007; Edward et al.,2006). It should be noted here that when the HIV/AIDS antibody test first became available in the 1985, many of those concerned with combating the infection spread opposed the idea of widespread testing (Serwadda et al., 1985; Wabwire-Mangeni et al., 2008). The simple reason was that little could be done for the person who had acquired the HIV infection and that it would not help in the 
prevention of its spread to other people. They did not consider the powerful message that would come out of the people who would live positively with it (Edward et al., 2006; Mugyenyi, 2008; Gonzalez, 1992).

Today, however there are antiretroviral drugs (ARVS) that when administered early can prevent, delay the onset of full blown AIDS and improve the quality of life of the victim. The best HCT program offers both the pre and post test counseling and treatment (Turner et al., 1988; Annabelle et al., 2011). There is speculation that it is possible to be HIV positive without developing AIDS (Mugyenyi, 2008). Those who have HIV positive results will be monitored, supported and counseled to live positively and studies have shown that it has helped them live longer, more productive and useful life. Currently there are people in Uganda on ARVS who have lived for over 20 years with HIV/AIDS (Turner et al., 1988; Annabelle et al., 2005; Wabwire-Mangeni et al., 2008). HCT is the best and objective way to diagnose HIV infection (Turner et al., 1988) and this study was designed to assess the knowledge, access and hindrances of HCT amongst the youths in this post-conflict area of Gulu.

\section{Materials and Methods Setting}

We conducted in-depth questionnaire interviews with youths of Commercial Road Parish. It is one of the parishes in Pece sub County of Gulu Municipality in Northern Uganda. This study was conducted from January to June 2009. Gulu Municipality is a city in northern Uganda and it is $343 \mathrm{~km}$ north of the capital Kampala. This place is just recovering from the 20 year old civil war. It is strategically located and endowed with its transport terminals and pivoted role in the vast and profitable distribution of goods in the region. It is the regional center for northern Uganda and draws a largely rural population; many of whom were displaced into camps famously known as the internally displaced peoples camps (IDPS) for safety from the insurgency. It shares borders with Southern Sudan where lucrative cross border trade takes place. It is also located on the highway of the "Great North Road" which runs from Cape Town in South Africa to Cairo in Egypt. According to the Revised Gulu District Development Plan 2009/2010, Gulu municipality has a population of 119,430 and composed of four sub counties; Pece, Laroo, Bardege and Layibi (GDPU, 2009/2010). Pece sub County has a population of 36,133 and composed of 4 parishes and 16 villages. One of the parishes is Commercial Road Parish with a population of 14,600 which was chosen as a study site purposively because of its high population density (14,600 people in 2.25 square kilometers and a youthly population of over $40 \%$ of the total population in the Parish. This Parish was massively affected by displacement of persons from the neighboring rural communities.

\section{Design}

This was cross-sectional study conducted among the youths 15 to 35 years using a prepared questionnaire designed for data collection.

\section{Selection of participants}

A total sample of 86 respondents was selected and we used questionnaires to collect data from respondents from different households to complete the numbers for the study. The study variables were controlled by interviewing only respondents, who were residents of the parish, had consented and of qualifying age. Questionnaires were administered by the interviewers at the respondents' residence to collect the data required. Informed verbal and written consents were obtained from the respondents before the indepth interviews were conducted and they had to freely agree to join the study and provide the required information. The questionnaire was pilot tested among the youths of Bar dege Sub county, Kasubi Parish in Gulu Municipality, and was designed to collect the background demographic data and the detailed information on HIV counseling and testing (HCT). After the test, it was improved to help the youths recall the HCT events and space added to consider other relevant information. The tested questionnaires were then administered to the respondents to obtain the accurate information needed. In order to avoid an unnecessary semantic misunderstanding, the questionnaire was written in simple English and translated into Luo, the main regional language by the investigators in conjunction with a trained interviewer and interpreter. The respondents were asked open-ended questions to describe their knowledge, attitude, hindrances and practices to HCT and also made to restate their information before entry in to the questionnaire. HIV counseling and testing (HCT) was defined as the process by which an individual, couple, or family receives HIV testing and counseling on HIV prevention, treatment, care, and support (Wabwire-Mangeni et al., 2008; Kitara et al., 2011). Extra spaces were used as qualifying remarks which aided considerably in giving answers to specific questions and providing additional information which assisted the researchers. During the data collection process, confidentiality, respect, privacy and high moral principles were observed. The sampling technique from the Parish to the village to households was consecutively conducted. In the households the youths were consecutively sampled for the interviews based on the village, informed consent and age. A maximum of 2 
youths were sampled per household. Overall 60 households were selected and samples of 86 youths were obtained.

\section{Data collection}

Questionnaire and interviews were used to collect data on the socio-demographic characteristics, the knowledge, attitudes and hindrances to the access of HCT services in the parish. Two trained research assistants, with the authors supervising, collected data. The two trained research assistants (1 male and 1 female) were Clinical officer students in their final year with experience in HIV/AIDS counseling and testing. The average length of each interview was 30 mins. The questionnaire interviews were conducted in English since most of the respondents could speak and understand English language well enough.

The Parish was visited between 8:30am and 5:30pm on weekdays and between 9:00pm and 4:00pm on Saturdays. These periods were the periods when respondents could be easily found at home.

Dependent variable: HIV/AIDS counseling and testing (HCT) among the youths in Commercial Road Parish. This was specifically to establish their knowledge, attitudes and hindrances to HCT.

Independent variables: These were sex, age, tribe, religion, level of education, occupation, marital status, the distance from the HCT centres, the hindrances to access to HCT.

\section{Analysis}

The data obtained were put in descriptive form and analyzed in percentages and fractions.

\section{Ethical consideration}

The study was approved by the Research and Ethics Committee of Gulu Regional Referral Hospital. Permission to collect data was sought from the owners and the managers of the barbershops. Informed consent was obtained from youths before the interviews.

Table 1: Data on Demographic characteristics of respondents

The ages of the respondents

\begin{tabular}{lrr}
\hline Age ranges & Frequency $(\mathrm{N}=86)$ & Percentage \\
\hline $15-19$ & 9 & 10.5 \\
$20-24$ & 21 & 24.4 \\
$25-29$ & 13 & 15.1 \\
$30-35$ & 43 & 50.0 \\
Level of Education of the respondents & & \\
Primary & 14 & 16.0 \\
secondary & 34 & 40.0 \\
Tertiary & 38 & 44.0 \\
Marital status of the respondents & & \\
Status & 32 & 37.0 \\
Married & 52 & 61.0 \\
Not Married & 2 & 2.0 \\
Divorced & & \\
Who does the respondent live with? & 83 & 97.0 \\
With Parents & 3 & 3.0 \\
on their own & & \\
Distances of respondents to HCT centres & 80 & 93.0 \\
$<1$ Km & 5 & 6.0 \\
1Km & 1 & 1.0 \\
$>$ I Km & 49 & 5.0 \\
Occupation of the respondents & 4 & 5.0 \\
Student & & \\
Pupils & & \\
Family Business & & \\
Peasant Farmer & & \\
\hline
\end{tabular}




\section{Results}

Data on Socio-demographic characteristics of the patients (Table 1)

The respondents' ages ranged from 15 to 35 with a mean of 31 years and the peak being 31-35 years. Female to male ratio was1.1:1. Thirty seven percent (37\%) of the youths were married, (61\%) were not married and (2\%) were divorced. Most respondents $(83.7 \%)$ had attained a post primary education and their occupation were mainly peasant farming (57\%) and nearly all the youths lived with their parents (97\%) and most were within $1 \mathrm{~km}$ from HCT centre (93\%)(Table 1).

Table 2: Data on HIV/AIDS Stigmatization

\begin{tabular}{lcr} 
Respondents & Frequency (N=86) & Percentage \\
\hline Those who have stigmatized & 77 & 90.0 \\
Have never stigmatized & 9 & 10.0 \\
The people who were stigmatized by the respondents & 4 & \\
Family members & 8 & 4.5 \\
Close friends & 63 & 8.9 \\
Someone they know & 11 & 73.3 \\
Stranger & & 13.3 \\
Views of the respondents to HIV/AIDS stigmatization & 48 & \\
Reduces HIV spread & 38 & 56.0 \\
Wouldn't reduce HIV Spread & & 44.0 \\
How respondents conducted HIV/AIDS stigmatization & 19 & \\
Verbal abuse & 19 & 22.0 \\
Pointing Accusing finger & 28 & 22.0 \\
Avoidance of a HIV victim & 5 & 33.0 \\
Denial of food to the Victim & 5 & 6.0 \\
Refusal to share utilities with the victim & 9 & 6.0 \\
Others & 9 & 11.0 \\
The evidence respondents used to characterize a person as & HIV positive & \\
Weight Loss & 8 & 10.0 \\
Red Lips & 7 & 9.0 \\
Body Rashes & 8 & 8.0 \\
Persistent cough & 15 & 9.0 \\
Loss of a spouse & 9 & 17.0 \\
Loss of a child and rumours & 23 & 11.0 \\
Seen the HIV test results & 8 & 27.0 \\
Person taking ARVS & & 9.0 \\
\hline
\end{tabular}

Data on the answers to HIV stigmatization (Tables 2 and 5a)

Most respondents had practiced HIV/AIDS stigmatization (90\%) and only $10 \%$ had not. There was fair knowledge of respondents to HIV stigmatization (49\%) but the majority $51 \%$ did not know what HIV stigmatization was. According to those who knew; verbal abuse, denial of food and refusal to share utilities was HIV stigmatization.

The most commonly stigmatized people by respondents were: Family members (4.5\%), friends (8.9\%), someone you know (73.3\%) and a stranger (13.3\%).

Most (56\%) respondents' reason for HIV/AIDS stigmatization was to reduce the spread of HIV while $44 \%$ believed it would not reduce HIV/AIDS spread. Most respondents (74\%) reported that they were informed about HCT through FM radios, (15\%) from friends, (10\%) from youth friendly clinics and (1\%) from others. The respondents acknowledged that they practiced stigmatization by; Avoidance of the victim (33\%), verbal abuse (22\%), pointing accusing finger on the victim (22\%), others (11\%) (Sharing of a bed etc), (6\%) denial of food to victim and refusal to share utilities respectively. The evidence used by respondents to characterize a person as HIV/AIDS positive were; Weight Loss (10\%), Red Lips (9\%), Body Rashes (8\%), Persistent Cough (9\%), Loss of a spouse (9\%), Loss of a child and rumours (11\%), Seen the HIV test results (27\%) and someone with a confirmed diagnosis and taking ARVS (Table 2). 
Table 3: Data on the respondents about HCT

\begin{tabular}{lcc} 
Knowledge on HCT & Frequency $(\mathrm{N}=86)$ & Percentage \\
\hline Adequate knowledge & 80 & 93.0 \\
Inadequate Knowledge & 6 & 7.0 \\
Knowledge about the benefits of HCT & & \\
Recognized the benefits of HCT & 84 & 97.7 \\
& & 2.3 \\
Does not know the benefits & 2 & \\
Sources of HCT information to the respondents & & 41.9 \\
Health workers & 36 & 12.8 \\
Friends & 11 & 26.7 \\
Radios & 23 & 18.6 \\
Others (News papers, social functions) & 16 & \\
Attendance of HCT by the respondents & & 36.0 \\
Undertook HCT & 31 & 64.0 \\
Has not undertaken HCT & 55 & \\
Recommendation by respondents on who should undertake & $\mathrm{HCT}$ & 39.5 \\
Students & 34 & 38.4 \\
Barmaids & 33 & 11.6 \\
Married Couples & 10 & 10.5 \\
Others & 9 & \\
\hline
\end{tabular}

Data on answers to the HIV counseling and testing (HCT) (Table 3)

Most respondents (93\%) had adequate knowledge on HCT while (7\%) had inadequate knowledge. Most respondents (41.3\%) received HCT information from health workers, (12.6\%) from friends, (26.9\%) from the media (Radio mainly) and (19.2\%) from the others e.g. newspapers, posters and functions and schools. On the benefits of HCT; most respondents (97.7\%) mentioned more than 2 benefits of HCT while $2.3 \%$ could not mention any benefit but recognized the danger of contracting HIV/AIDS as one of the benefits. Most respondents (97\%) knew the location of the youth friendly clinics whereas 3\% did not know. The youth friendly clinics were those clinics established by the Uganda Ministry of Health in all districts of Uganda and they provide free and an interrupted HCT services to youths. Respondents' attitudes towards HIV testing was; Forty three (43\%) would not test for HIV/AIDS while (57\%) would test for the virus. Most respondents (82\%) who would get tested could easily disclose their status while only (18\%) felt uncomfortable about disclosing their HIV status.

Most respondents (39.5\%) recommended that HCT services should be provided to the students, (38.4\%) to Barmaids, and (11.6\%) to married couples and $(10.4 \%)$ to the others.

Most respondents (88.4\%) agreed that it was proper to discuss HCT results openly to colleagues, friends and the public. Those who expressed positive attitudes towards discussing HCT openly reported that they would feel free to talk about it with a health worker mainly, then a friend who keeps secrets, a wife or a girlfriend. However, (11.6\%) reported that it was not proper to discuss the HCT openly. However, those who said it was not proper to discuss HCT openly said they would only consider discussing it with a health worker otherwise they would prefer to keep the information to themselves because of the fear of stigmatization (Table 3).

\section{Data on reasons for poor access to HCT (Table 4)}

The reasons why respondents were not undertaking HCT were: Most respondents (70\%) feared stigmatization, (7\%) due to fear of knowing one's HIV status, (8\%) because of fear of being identified as HIV victim, (10\%) was due to self denial/ loss of self-esteem and getting responsible for their HIV status, (5\%) due to other reasons such as loss of boy/girlfriends.

Data on other variables explored (Tables 5a, b)

Feelings of respondents towards other people undertaking HCT were that; most respondents (84.9\%) approved that more people should undertake HCT and (12.8\%) were not bothered about others whereas $2.3 \%$ could only sympathize with those that had not undertaken HCT.

It should be noted that the attendance of HCT among respondents was that only $36.1 \%$ of respondents had ever undertaken HCT and $63.9 \%$ had not undertaken and were not planning to do so in the near future. 
Table 4: Data on Reasons for Poor access

\begin{tabular}{lcc} 
Reasons for poor access & Frequency $(\mathrm{N}=55)$ & Percentage \\
\hline Fear of Stigmatization & 38 & 70.0 \\
Fear of Rejection by friends & 4 & 8.0 \\
Fear of knowing HIV status & 4 & 7.0 \\
Fear of Denial/Loss of self esteem & 6 & 10.0 \\
Others & 3 & 5.0 \\
\hline Total & 55 & 100.0
\end{tabular}

Most respondents (70.9\%) who undertook HCT were females and $29.1 \%$ males. Only (36.1\%) of respondents undertook HCT. With regards to the number of sessions undertaken, $9.7 \%$ visited once, $58.1 \%$ visited twice and $32.2 \%$ visited HCT more than twice. The majority of the respondents $(67.8 \%)$ did not complete the required number of sessions as prescribed by the Ministry of Health protocol for HCT (total of at least 3 sessions conducted consecutively in a period of six months).

With regards to attending HCT together as a couple: Out of the 31 couples that undertook HCT, 80.6\% undertook HCT without their partners while only $19.4 \%$ attended with their partners. Among those who did not undertake HCT with their partners, $68.0 \%$ discussed test results with their partners while $32 \%$ of those who tested as a couple did not disclose their status to partner.

With regards to the number of sexual partners; few respondents (22\%) had a single sexual partner, 33\% had two sexual partners and $45 \%$ had more than three sexual partners concurrently. Most respondents with a single sexual partner (58\%) were females and the rest males.

Table 5(a): Data on other variables

The respondents rating to determine the level of knowledge and attitudes to HCT

Knowledge to HCT Ratings

\begin{tabular}{|c|c|c|}
\hline Variables & Adequate & Inadequate \\
\hline Define HCT & Can define HCT & Unable to define HCT \\
\hline How it is conducted & $\begin{array}{l}\text { Can explain a process of } \\
\text { HCT }\end{array}$ & $\begin{array}{l}\text { Couldn't explain the process of } \\
\text { HCT } \\
\text { Couldn't mention any uses of }\end{array}$ \\
\hline The uses of HCT & $\begin{array}{l}\text { Gives at least } 4 \text { uses of } \mathrm{HCT} \\
\text { Mentions } 3 \mathrm{HCT} \text { sites in the }\end{array}$ & HCT \\
\hline Where it is conducted & $\begin{array}{l}\text { area } \\
\text { Mentions at least } 2 \text { obstacles }\end{array}$ & Knows the HCT sites in the area \\
\hline The obstacles to HCT & to $\mathrm{HCT}$ & Couldn't mention any obstacles \\
\hline \multicolumn{3}{|c|}{ The Respondents' Attitudes to HCT } \\
\hline Variables & Poor & Good \\
\hline Disclosure of HCT results & Does not & $\begin{array}{l}\text { Does not } \\
\text { Willing to undertake/Undertaken }\end{array}$ \\
\hline Undertaking HCT & Not willing to undertake $\mathrm{HCT}$ & $\begin{array}{l}\mathrm{HCT} \\
\text { willing to convince others to }\end{array}$ \\
\hline Those who haven't taken HCT & Does not care & undertake HCT \\
\hline Knowledge of HCT sites & Not interested in Knowing & Knows the HCT sites in the area \\
\hline
\end{tabular}

\section{Discussion}

Most of the respondents' homes were located within one kilometer from the HCT centres. The location of the homes of the youth did not negatively influence their access to the HCT centres which were mainly located near the parish and these centres were not charging any fee (Table 1). The reason cited most for lack of access was the fear of stigmatization from the community (Table 4). This study did not note any specific problems of breach of confidentiality or parents preventing the youths from undertaking HCT that could deter the youth from accessing HCT centres. Youths as young as 12 years in Gulu could undertake HCT without the consent of the parents and in the absence of the parents (UNAIDS, 2009), (Wabwire-Mangen et al., 2008). This made it clearer that in spite of the available HCT services at no fee and at close proximity to the youths, only a few youths undertook HCT (Table 3)

HIV/AIDS stigmatization is not a straightforward phenomenon because the attitudes towards the epidemic and those affected vary massively (Ban Ki-moon, 2008b). It should be noted that AIDS-related 
stigma is not static. It changes over time as HIV infection levels, knowledge of the disease and treatment availability varies (UNAIDS, 2008). We wish to observe here that even within our country, reactions to HIV/AIDS will vary between individuals, groups of people, religion, gender, sexuality, age and levels of AIDS education because all affect how somebody feels about HIV/AIDS and their responses (UNAIDS, 2008). We note here that from early in the AIDS epidemic in Uganda, a series of powerful images were used that reinforced and legitimized stigmatization (WHO, 2003; Makoae, 2009; Edward et al.,, 2006). HIV infection was looked at as punishment (e.g. for immoral behaviour), HIV/AIDS as a crime (e.g. in relation to innocent and guilty victims), HIV/AIDS as a war (e.g. in relation to a virus which must be fought), HIV/AIDS as horror (e.g. in which infected people are demonized and feared), HIV/AIDS as otherness (in which the disease is an affliction of those set apart) (WHO, 2003; Makoae et al., 2009). The youths in the post-conflict Gulu were not spared from this kind of messages, infact the civil war, the displacement in to camps (IDPS) and the urban life experiences further created a more negative attitude towards behaviour change as had earlier on been propagated in Uganda and which created the greatest impact in the reduction in the prevalence of HIV/AIDS in Uganda from 29\% in the 80s to less than10\% in 2000 (Wabwire-Mangen et al.,, 2008; Kitara et al., 2011; Edward et al., 2006). UN Secretary-General Ban Ki Moon says, "Stigma remains the single most important barrier to public action. It is a main reason why too many people are afraid to see a doctor to determine whether they have the disease, or to seek treatment. It helps make AIDS the silent killer, because people fear the social disgrace of speaking about it, or taking easily available precautions”.

Most of the youth in this community (90\%) practiced HIV stigmatization using different forms of methods to stigmatize their victims (Table 2) and this may probably be the reason behind the increasing prevalence and incidence of HIV/AIDS among the youth of Gulu in Northern Uganda (UNAIDS, 2010). This was also observed by the UN secretary General who noted rightly that HIV Stigmatization is one of the chief reasons why the AIDS epidemic continues to devastate societies around the world. The youth noted that HIV Stigmatization does not only make it more difficult for them to try to come to terms with HIV and manage their illness on a personal level, but also that it interfered with their attempts to fight the HIV/AIDS epidemic including the fear to undertake HCT as the beginning of a continuum for HIV care and support (UNAIDS, 2008; WHO, 2003) (Table 3).

On a national level in Uganda, the stigma associated with HIV was observed to be a possible deterrent of the government from taking fast, effective action against the epidemic, whilst on a personal level it could make individuals reluctant to access HIV counseling and testing (HCT), treatment and care (UNAIDS,2008), (WHO, 2003). This was similarly observed in this study (Table 3). Our study defined HIV/AIDS-related stigma and discrimination as prejudice, negative attitudes, abuse and maltreatment directed at people living with HIV/AIDS (Makoae et al., 2009; Roura et al., 2009; Wolfe et al., 2008) and that for the youth, HIV stigmatization could lead them to being shunned by family, peers and the wider community; thus an erosion of their rights, psychological damage, and could negatively affect their success of HIV testing and treatment (Makoae et al., 2009; Roura et al., 2009; Wolfe et al., 2008) . This was clearly observed in this study where over $70 \%$ of respondents feared to undertake HCT because of fear of stigmatization from the community (Table 4). Fear of contagion coupled with negative, value-based assumptions about people who are infected leads to high levels of stigma surrounding HIV/AIDS (UNAIDS, 2008; Makoae et al., 2009; Wolfe et al., 2008) and this was clearly shown by these youths (33\%) avoiding their colleagues who were confirmed or perceived to be HIV positive (Table 2). Most people in Uganda become infected with HIV through heterosexual intercourse which often carries moral baggage (Wabwire-Mangen et al., 2008), and there is a lot of inaccurate information about how HIV is transmitted, creating irrational behaviour and misperceptions of personal risk especially on the issue of concurrent multiple sexual partners seen among these youths (Table 4).

HIV infection is often thought to be the result of personal irresponsibility (Wolfe et al., 2008). Religious or moral beliefs lead some people to believe that being infected with HIV was a result of moral fault (such as promiscuity or 'deviant sex') that deserved to be punished and in some circumstances, even undertaking HCT would portray that someone is promiscuous (Wolfe et al., 2008). These messages have probably created one of the greatest fear factors in this community of youths thus leading to further stigmatization and avoidance of HCT services (Table 4).

A study of 1,268 adults in Botswana found that HIV stigmatizing attitudes had lessened three years after the national program providing universal access to treatment was introduced. The study concluded that although improving access to antiretroviral treatment may be a factor in reducing stigma, it does not eliminate stigma altogether and does not lessen the fear of stigma amongst HIV positive people (IPPF, 2009). Moreover, as there are many types of stigma it is possible that the availability of treatment may reduce some types of stigma and not others (IPPF, 2009). Treatments for HIV patients has been available in Uganda for over 10 years and yet the HIV stigma still rages on (UNAIDS, 2010; Wabwire-Mangen et al., 2008). Therefore this result confirms the uniqueness of individual in some areas and factors that influence their response to HCT services (Table 5). In a matter of fact that stigma still remains in developed countries such as America, where treatment has been widely available for over a decade, it indicates that the relationship between HIV treatment and stigma is not straightforward. An estimated 27\% of Americans would prefer not to work closely with a woman living with HIV (IRIN, 2005). Moreover, preliminary results from the People Living with HIV Stigma Index found that $17 \%$ of respondents living with HIV in the UK had been denied 
health care and that verbal harassment or assault had been experienced by $21 \%$ of respondents (Ogden and Nyblade, 2005; UNAIDS, 2010). These extreme responses though were not experienced among the respondents in our study.

HIV-related stigma and discrimination severely hamper efforts to effectively fight the HIV/AIDS epidemic. Fear of discrimination often prevents people from seeking HCT and treatment for AIDS or from admitting their HIV status publicly (Table 4). People with or suspected of having HIV may be forced from home by their families and rejected by their friends and colleagues (Table 4). Denial goes hand in hand with discrimination, with many people continuing to deny that HIV exists in their communities and in individuals (Mugyenyi, 2008).

We take note that our study showed that most respondents had two or more sexual partners simultaneously while only a quarter had a single partner in the last five years. Many youths in Uganda feel that they are invincible and that nothing bad will happen to them; many more still belief that HIV does not cause AIDS (Mugyenyi, 2010; Wambayi, 2005). Only a third of the respondents had ever undertaken HCT (Table 3).

Young people in Uganda will remain at the centre of the HIV/AIDS epidemic in terms of rates of infection, vulnerability, impact, and potential for change (UNAIDS, 2008). They have grown up in a world changed by AIDS but many still lack comprehensive and correct knowledge about how to prevent HIV infection. They are disproportionately affected in the HIV pandemic (Kitara et al., 2011). They face the economic and social impact of HIV/AIDS on families, communities, and nations, and they are at the centre of prevention actions (Kitara et al., 2011). Where young people are well informed of HIV risks and prevention strategies, they are changing their behaviour in ways that reduces their vulnerability (UNAIDS, 2008).

The vast majority of HIV infections in Uganda occur in the population segment between ages 15 and 49 years (UNAIDS, 2010). Most males were unwilling to come to know their HIV status (Kitara et al., 2011). Often they had a negative attitude towards the services offered by voluntary counseling and HIV/AIDS testing (HCT) for fear of status being revealed that they were HIV positive and therefore stigmatized (Mugyenyi, 2008; Kitara et al., 2011). The fear and prejudice that lie at the core of the HIV/AIDS-related discrimination needs to be tackled at the individual, community and national levels, with AIDS education playing a crucial role (Ban Ki-moon, 2008a), (UNSS, 2004/05; Kitara et al., 2011). A more enabling environment needs to be created to increase the visibility of people with HIV/AIDS as a 'normal' part of any society (IRIN, 2005; Ban Ki-moon, 2008b; UNSS, 2004/05). The task is to confront the fear-based messages and biased social attitudes, in order to reduce the discrimination and stigmatization of people living with HIV/AIDS (UNAIDS, 2010; UNSS, 2004/05).

\section{Conclusion}

There is adequate knowledge on HCT, good attitude, adequate access to HCT centres but poor practices among the youths. There is a very high level of HIV stigmatization amongst the youths (90\%) preventing them from undertaking HCT.

\section{Recommendation}

The Uganda Ministry of Health should strengthen the monitoring of HCT services in all the health facilities and design a focused program to target the youths and discourage them from using stigmatization as HIV prevention strategy. Since HIV/AIDS is a social problem, its prevention can best be achieved through persuasion of the youth towards behaviour change. More emphasis should be laid on the psychosocial support of the youths to overcome HIV/AIDS stigmatization. African border towns and cities should watch out on the unique situation experienced by the youths in such sites. Gulu being an area in the post-conflict situation and an urban area which is close to the border with South Sudan and in a highway should be targeted with a special support in HIV prevention.

\section{Acknowledgement}

We acknowledge the support of Gulu Hospital for the human and financial support for this study.

\section{References}

1. Annabelle S, Roura M, Zaba B, Todd J, Mark U (2011). Stigma in the Publication of Evidence for Action Policy Briefing balance: Ensuring the roll-out of ART decreases stigma. Communication initiatives(Ci)Ban Ki-moon op-ed (2008 a,b). The stigma factor. The Washington Times, New York, USA.

2. Ban Ki-moon op-ed (2008 a,b). The stigma factor. The Washington Times 
3. Cohen PT, Merle A, Paul AV (1994). The AIDS Knowledge Base: Nursing Practice eds N Engl J Med; 331:341-6.

4. Edward CG, Daniel TH, Vinand N, Janice AH (2006).Uganda's HIV Prevention Success: The Role of Sexual Behaviour change and Natural response. AIDS \& Behaviour; 10(4):335-346.

5. Epstein H (2007). The invisible cure. Africa, the west and the fight against AIDS. A Publication on Global disasters in 2008; 326.

6. GDPU (2009). The Gulu District Planning Unit report. A Publication of the Gulu Local Government Gulu, Uganda of 2010.

7. Gonzalez J (1992). HIV-2 Infection in high-risk individuals with indeterminate HIV-1 western blot analysis: A serological surveillance. The Good Health Fact Book. Blackwell Publishing Ltd. 62(4):244-245.

8. IRIN (2005). Keep quiet if you have AIDS or you will become an outcast'. Humanitarian news \& Analysis. A service of the UN office for the coordination of humanitarian affairs- /PlusNews 2005, Lebanon, Middle East.

9. IPPF (2009). HIV stigma and discrimination remain a significant challenge in the UK. A Publication of the International Planned Parenthood Federation (IPPF), London, UK.

10. Kitara DL, Bwangamoi PO, Odong S, Acullu D (2011). HIV/AIDS stigmatization amongst the youths in Gulu, Northern Uganda: A major drawback in the fight against the spread of HIV/AIDS. J Med. Med Sci; 2(4):805-811.

11. Makoae LN, Carmen JP, Leana RU, Priscilla SD (2009).The impact of taking or not taking ARVS on HIV stigma as reported by persons living with HIV infection in five African countries. AIDS care; 21(11):1357-1362

12. Margaret WV, Marion O’Reilly, Mary Y (2000). The humanitarian program on HIV and AIDS, a practical approach to HIV mainstreaming. New Vision newspaper Dec.9, 2008, Kampala, Uganda.

13. Montgomery BD (1992).The critical care nursing: Body-mind-spirit. Lippincott Williams \& Wilkins Publications ( $3^{\text {rd }}$ Edition), Texas, USA.

14. Mugyenyi P (2008). Genocide by Denial. New Vision newspaper Nov, 3, 2008, Kampala, Uganda.

15. Mugyenyi Peter (2010). Testimony to US Congress: House Committee on Foreign Affairs, Subcommittee on Africa and Global Health. New Vision newspaper, 2010, Kampala, Uganda.

16. Ogden J, Nyblade L (2005). HIV-related stigma across contexts: common at its core. A Publication of the International centre for women (IRCW-2005); London, UK.

17. Pratt JR (1988). AIDS - a strategy for nursing care. Edward Arnold Publisher, London, UK.

18. Roura M, Wringe A, Busza J, Nhandi B (2009). 'Just like fever": a qualitative study on the impact of antiretroviral provision on the normalization of HIV in rural Tanzania and its implications for prevention. BMC Int Health Hum Rights; 9; 9:22.

19. Serwadda D, Mugerwa R, Sewankambo N, Lwegaba A (1985). Slim Disease: A New Disease in Uganda and its Association with HTLV-III Infection. Lancet; 2(8460):849-852.

20. Turner FC, Heather G, Muller and Lincoln EM (1988): AIDS-Sexual behaviour and intravenous drug use. National Academics press 1995:334.

21. UNAIDS (2009). Knowledge is Power: Voluntary HIV Counseling and Testing in Uganda. GoU/UNAIDS, Kampala, Uganda.

22. UNAIDS (2008). UNAIDS 2008 Report on the global AIDS epidemic. WHO Library Cataloguingin-Publication Data, Geneva, Switzerland.

23. UNAIDS (2010). UNAIDS 2010 Report on the global AIDS epidemic. WHO Library Cataloguingin-Publication Data, Geneva, Switzerland.

24. UNSS (2004/2005). Uganda National Sero Behavioural Survey 2004/2005, Ministry of Health, GoU/UAC/UNAIDS, Kampala, Uganda.

25. Wabwire-Mangen F, Odiit M, Kirungi W (2008). Modes of Transmission Study, Analysis of HIV Prevention Response and Modes of HIV Transmission, the Uganda Country Synthesis Report, GoU/UNAIDS/UAC. 2008, Kampala, Uganda.

26. Wambayi E (2005). External consultant in consultancy Africa intelligence's HIV/AIDS unit (hiv.aids@consultancyafrica.com).

27. WHO (2003). Treating 3 Million by 2005: Making it Happen. The WHO \&UNAIDS Global initiative to provide Antiretroviral therapy to 3 million people with HIV/AIDS in developing countries by the end of 2005. WHO Library Cataloguing-in-Publication Data, Geneva, Switzerland.

28. William A (1988). AIDS: Medical Disorders and their treatment, The Encyclopedia of health. A Publication by Chelsea House Pub (L), London, UK.

29. Wolfe WR; Weiser SD, Leiter K, Steward WT (2008). The impact of Universal access to antiretroviral therapy on HIV stigma in Botswana'. Am J Public Health; 98(10):1865-71. 